\title{
Avoidance of patent anterior grafts at revisional coronary artery surgery: use of a lateral thoracotomy
} approach

\author{
W S WALKER, C T M SANG \\ From the Department of Cardiac Surgery, Edinburgh Royal Infirmary, Edinburgh
}

\begin{abstract}
The use of a right or left lateral thoracotomy is described as an alternative approach to revisional coronary artery surgery for patients with patent anterior grafts. Five patients underwent successful revisional coronary artery grafting with a total of three internal mammary artery grafts and three saphenous vein grafts. This is a safe technique in patients for whom repeat median sternotomy is potentially hazardous, notably those with patent anterior grafts or close apposition of the heart to the sternal table.
\end{abstract}

Revisional surgery for patients who have undergone coronary artery bypass grafting is likely to increase considerably within the next decade $^{1}$ because of occlusion of existing grafts or progression of disease in previously ungrafted vessels, ${ }^{2-4}$ or both. Generally, mortality rates are somewhat higher than for the first operation, ${ }^{15}$ although results approaching those of the initial procedures may be achieved. ${ }^{2-4}$ Perhaps the greatest hazards of revisional surgery are injury to patent anterior grafts and catastrophic haemorrhage from damage to one of the cardiac chambers at the time of sternal re-entry. ${ }^{6}$ Injury to patent grafts is especially dangerous, with an associated mortality rate of up to $50 \%{ }^{6}$ We wish to highlight an alternative approach to repeat median sternotomy for revisional coronary artery bypass grafting, based on a right or left lateral thoracotomy, which we have used successfully in five patients, to avoid the risk of injury to patent anterior grafts. We believe that others may find this technique of value and wish to emphasise the availability of the internal mammary artery at lateral thoracotomy.

\section{Patients and technique}

Details of the patients are summarised in table 1 and the operative technique in table 2. Patients were positioned and draped for anterolateral thoracotomy to

Address for reprint requests: Mr WS Walker, FRCS, Department of Cardiac Surgery, Edinburgh Royal Infirmary, Edinburgh

Accepted 24 March 1986 allow access to both groins, and to an appropriate $\stackrel{\infty}{\circ}$ segment of saphenous vein where this was to be used for grafting. The upper groin was dissected to expose the femoral vessels at the same time as the thoracotomy was performed. When the chest had been opened the internal mammary artery was dissected out in those cases where it was planned to use this as a graft.

For a left sided approach initial partial bypass was established with venous drainage from the left common femoral vein and arterial return to either the left femoral artery or the descending thoracic aorta. When partial bypass had been started a venous cannula was inserted into the pulmonary artery, thus providing sufficient drainage to achieve the predicted bypass 3 flow. For a right sided approach conventional venous drainage was effected via transatrial caval pipes with 3 arterial return to the right femoral artery.

With the institution of bypass, systemic cooling was carried out, the heart was electively fibrillated, and, when the operation was performed from the left side, a left ventricular apical vent was usually inserted. $\sigma$ It was found that previous grafts could be palpated $N$ and therefore avoided while the pericardium was $N$ being opened. Coronary occluders (Surgitext, Xomed, Zimmer Bros, Swindon) were used to enhance the operating conditions while the distal anastomoses? were being made. Vein grafts were placed from the thoracic aorta to circumflex vessels, the left pulmonary ligament being divided to provide the most 0 direct route. The chest was closed routinely with peri- $\overrightarrow{\mathbb{D}}$ costal and layered polyglycolic acid sutures, and basal $\frac{\mathrm{O}}{\mathrm{D}}$ and apical underwater seal drains were used. 
Avoidance of patent anterior grafts at revisional coronary artery surgery: use of a lateral thoracotomy approach

Table 1 Revisional coronary artery grafting via lateral thoracotomy: summary of data on the patients

\begin{tabular}{|c|c|c|c|c|c|c|c|}
\hline $\begin{array}{l}\text { Patient } \\
\text { No }\end{array}$ & Age (y) & $\operatorname{Sex}$ & $\begin{array}{l}\text { NYHA } \\
\text { grade }\end{array}$ & $\begin{array}{l}\text { Time since } \\
\text { previous } \\
\text { surgery }\end{array}$ & $\begin{array}{l}\text { Previous surgery, } \\
\text { current state of graft }\end{array}$ & $\begin{array}{l}\text { Indication for } \\
\text { revisional } C A B G\end{array}$ & $\begin{array}{l}\text { Indication for } \\
\text { thoracotomy } \\
\text { approach }\end{array}$ \\
\hline 1 & 58 & $\mathbf{M}$ & III & 9 months & $\begin{array}{l}\text { SV sequ: LAD, LADD } \\
\text { (blocked) } \\
\text { SV: RCA endart } \\
\text { (patent) }\end{array}$ & $\begin{array}{l}\text { Blocked LAD, LADD } \\
\text { graft }\end{array}$ & Patent RCA graft \\
\hline 2 & 57 & $\mathbf{M}$ & IV & 129 months & $\begin{array}{l}\text { SV: LAD, endart } \\
\text { (patent) } \\
\text { SV: RCA (blocked) } \\
\text { LV plication }\end{array}$ & $\begin{array}{l}\text { Progression of } \mathrm{Cx} O \mathrm{OM} \\
\text { branch disease }\end{array}$ & Patent LAD graft \\
\hline 3 & 46 & $\mathbf{F}$ & IV & 88 months & SV: LAD (patent) & $\begin{array}{l}\text { Progression of } \mathrm{Cx} O M \\
\text { branch disease }\end{array}$ & Patent LAD graft \\
\hline 4 & 42 & $\mathbf{M}$ & $\begin{array}{l}\text { IV } \\
\text { isosorbide } \\
\text { infusion }\end{array}$ & 21 months & $\begin{array}{l}\text { SV: LAD (patent) } \\
\text { SV: LADD (patent) } \\
\text { SV: OM Cx (patent) }\end{array}$ & $\begin{array}{l}\text { Progression of RCA } \\
\text { disease, }\end{array}$ & Patent grafts \\
\hline 5 & 62 & $\mathbf{M}$ & IV & 16 months & $\begin{array}{l}\text { SV: LAD, LADD } \\
\text { (blocked) } \\
\text { SV: OM1, OM2 } \\
\text { (blocked) } \\
\text { SV: RCA (patent) }\end{array}$ & $\begin{array}{l}\text { Blocked LAD, LADD, } \\
\text { and OM1 and } \\
\text { OM2 grafts }\end{array}$ & Patent RCA graft \\
\hline
\end{tabular}

SV - saphenous vein; LAD — left anterior descending artery; LADD _ diagonal branch of LAD; OM-obtuse marginal branch of circumflex artery (Cx); RCA - right coronary artery; sequ - sequential; LV-left ventricle; endart—endarterectomy; CABG—coronary artery bypass grafting.

Table 2 Revisional coronary artery grafting via lateral thoracotomy: summary of operative details

\begin{tabular}{|c|c|c|c|c|c|}
\hline $\begin{array}{l}\text { Patient } \\
\text { No }\end{array}$ & $\begin{array}{l}\text { Thoracotomy } \\
\text { approach }\end{array}$ & Cannulation for bypass & Perfusion data & Procedure & $\begin{array}{l}\text { Postoperative } \\
\text { course }\end{array}$ \\
\hline 1 & Left 5 th rib & $\begin{array}{l}\text { Arterial: LFA } \\
\text { venous: LFV, PA } \\
\text { vent: } L V \text { apex }\end{array}$ & $\begin{array}{l}\text { Bypass } 116 \mathrm{~min}, \text { cooling } \\
\text { to } 30^{\circ} \mathrm{C} \mathrm{VF}\end{array}$ & LIMA: LAD SV: LAD & $\begin{array}{l}\text { Mild Erb's } \\
\text { Palsy }\end{array}$ \\
\hline 2 & Left 5th rib & $\begin{array}{l}\text { Arterial: desc thoracic aorta } \\
\text { venous: LFV, PA } \\
\text { vent: LV apex }\end{array}$ & $\begin{array}{l}\text { Bypass } 91 \text { mins, cooling to } \\
30^{\circ} \mathrm{C} \text {, VF }\end{array}$ & $\begin{array}{l}\text { SV: OM Cx (from desc } \\
\text { thoracic aorta) }\end{array}$ & Uneventful \\
\hline 3 & Left 5th rib & $\begin{array}{l}\text { Arterial: desc thoracic aorta } \\
\text { venous: LFV, PA } \\
\text { vent: } \text { LV apex }\end{array}$ & $\begin{array}{l}\text { Bypass } 61 \mathrm{~min} \text {, cooling to } \\
27^{\circ} \mathrm{C} \text {, VF }\end{array}$ & $\begin{array}{l}\text { SV: OM Cx (from desc } \\
\text { thoracic aorta) }\end{array}$ & Uneventful \\
\hline 4 & Right 6th rib & $\begin{array}{l}\text { Arterial: REA } \\
\text { venous: IVC, SVC } \\
\text { vent: nil }\end{array}$ & $\begin{array}{l}\text { Bypass } 48 \mathrm{~min} \text {, cooling to } \\
28^{\circ} \mathrm{C} \text {, VF }\end{array}$ & RIMA: RCA & Uneventful \\
\hline 5 & Left 6th rib & $\begin{array}{l}\text { Arterial: desc thoracic aorta } \\
\text { venous: LFV, PA } \\
\text { vent: nil }\end{array}$ & $\begin{array}{l}\text { Bypass } 87 \text { mins, cooling to } \\
29^{\circ} \mathrm{C} \text {, VF }\end{array}$ & LIMA: LAD & Uneventful \\
\hline
\end{tabular}

LFA - left femoral artery; LFV-left femoral vein; PA-pulmonary artery; RFA-right femoral artery; LIMA-left internal mammary; RIMA - right internal mammary; VF-ventricular fibrillation; desc-descending. See also footnote to table 1.

Although adhesions were encountered, these proved much less troublesome than those we experience at conventional repeat median sternotomy and problems of bleeding did not occur. One patient developed a minor degree of Erb's palsy, which responded well to physiotherapy, and one required low dose inotropic support on the night of surgery. All patients made good recoveries and were discharged to their homes or to convalescence between 8-11 days after operation.

\section{Discussion}

The use of a left lateral thoracotomy approach has been described in a total of 18 patients having revisional coronary artery bypass grafting, $^{7-9}$ although we are not aware of any previously reported use of a right thoracotomy for this purpose. Several technical points arise from our experience and deserve emphasis.

Firstly, with regard to cannulation, we found the addition of a venous cannula in the pulmonary artery of benefit for achieving venous drainage adequate to attain full flow. As noted by Ungerleider et al ${ }^{9}$ femoral arterial cannulation for arterial return is not required when the left approach is used as this can be achieved by direct cannulation of the descending thoracic aorta with a flexible armoured cannula with a long tip.

Secondly, the right or left internal mammary artery 


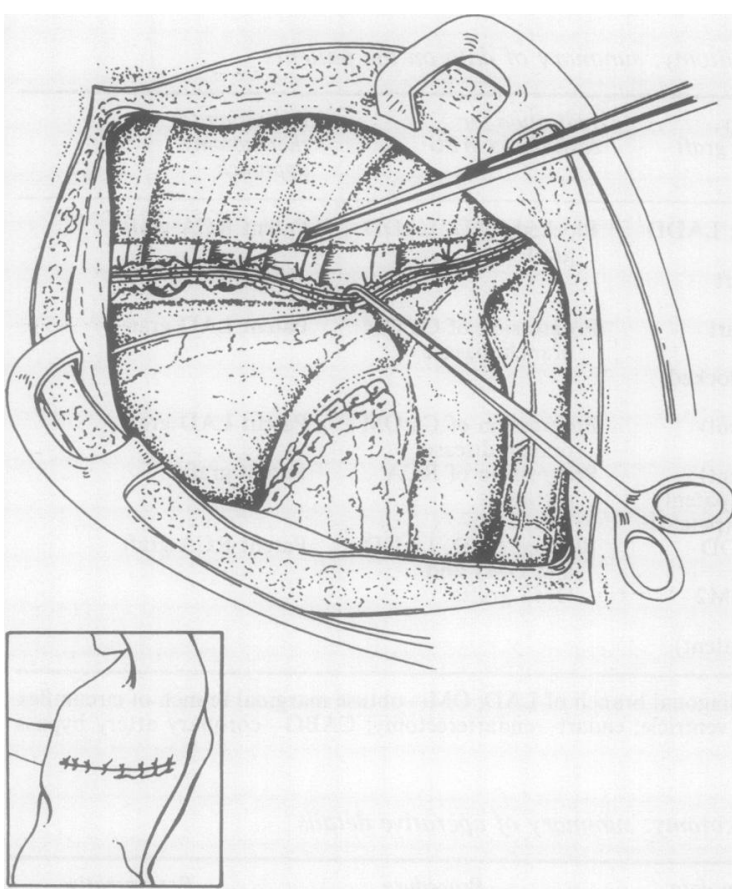

Fig 1 View of the internal mammary dissection at thoracotomy. is if anything more easily taken down with this approach (fig 1), although access is restricted to the $\bar{O}$ ipsilateral artery. Indeed, the first attempts to use this graft were made through a lateral thoracotomy. ${ }^{10}$ The ready availability of the internal mammary artery is a considerable advantage in view of the desirability of using this conduit wherever possible in revisional surgery when previous vein grafts have failed.

Thirdly, when the operation is performed from the left, we have found that, contrary to the observations of Cheung et al, ${ }^{7}$ opening the pericardium posterior to the left phrenic nerve is preferable as blood tends to accumulate within a pericardial pocket if the incision is made anteriorly, thus obscuring the operative field for proximal circumflex grafts.

Fourthly, unlike previous authors, we have found that we can conveniently place saphenous vein grafts directly in the circumflex system from the descending $c s$ aorta (fig 2) after the pulmonary ligament has been mobilised rather than constructing a $U$ shaped graft below the ligament ${ }^{7}$ from the descending aorta or leading a graft down from the subclavian artery. ${ }^{89}$

Finally, one of the advantages of the approach is $\vec{\bullet}$ the avoidance of dissection anteriorly, where adhe- $\%$ sions are thickest and patent grafts at risk; but this has created some difficulty in subsequent cardioversion from fibrillation at the end of the procedure through a right thoracotomy, as internal paddles could not be

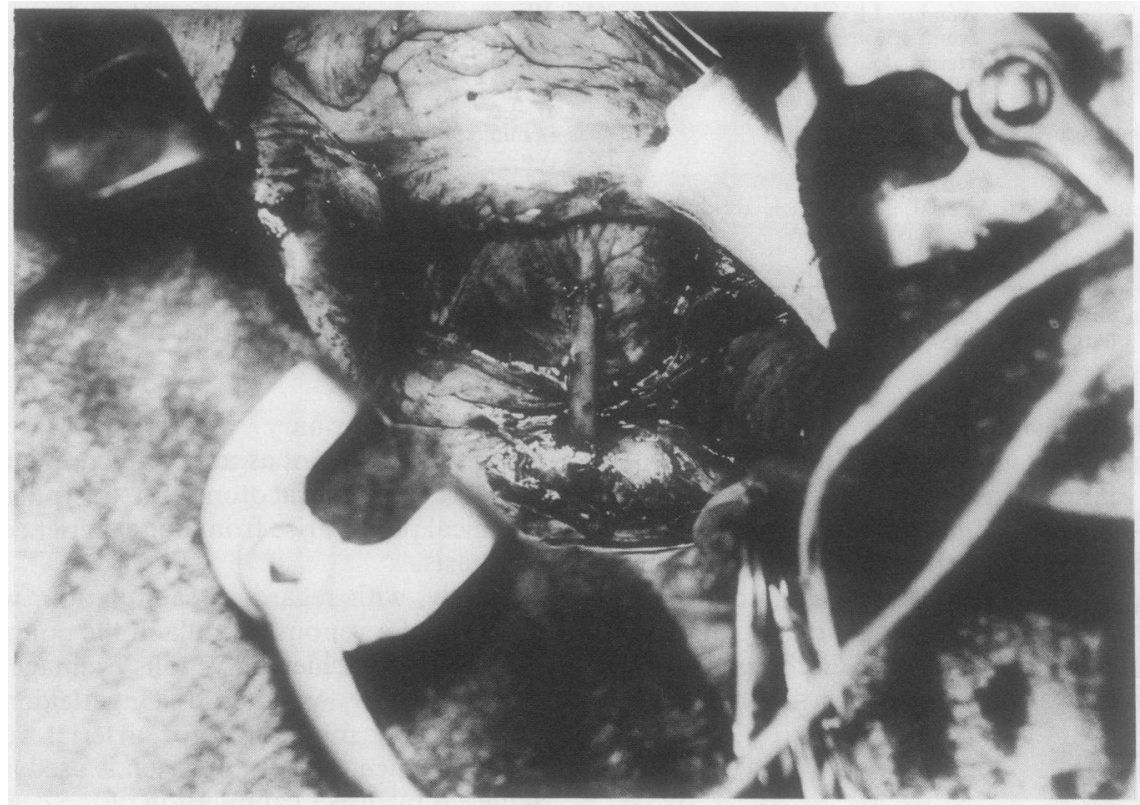

Fig 2 Straight saphenous vein graft from the aorta to the obtuse marginal branch of the circumflex coronary artery. 
placed sufficiently across the left ventricle. We dealt with this problem by the use of an external left paddle, and we would therefore suggest that on these occasions a sterile external paddle should be available to allow an adequate current across the myocardium.

This technique for revisional coronary artery grafting should be of particular value in those patients with patent anterior grafts. In this context, right coronary and internal mammary artery grafts are especially at risk and a long mammary pedicle may constitute a further hazard. ${ }^{411}$ Even if patent anterior grafts are not lacerated, the handling necessary with a median sternotomy approach may be dangerous as vein grafts of any age are likely to have degenerative changes, so that manipulation may lead to the possibility of embolisation of mural plaque and consequent infarction. Other patients likely to benefit from this approach are those in whom previous cardiac or mediastinal surgery has lead to close apposition of the heart to the posterior sternal table or in whom radiotherapy has obliterated the mediastinal plane, ${ }^{9}$ and patients for whom combined pulmonary surgery and coronary artery bypass grafting to ipsilateral vessels is envisaged. ${ }^{89}$

\section{References}

1 Loop FD, Lytle BW, Gill CC, Golding LAR, Cosgrove DM, Taylor PC. Trends in selection and results of coronary artery re-operations. Ann Thorac Surg 1983;36:380-8.

2 Loop FD, Cosgrove DM, Kramer JR, et al. Late clinical and arteriographic results in 500 coronary artery reoperations. J Thorac Cardiovasc Surg 1981;81:675-85.

3 Allen RH, Stinson EB, Oyer PE, Shumway NE. Predictive variables in re-operations for coronary artery disease. J Thorac Cardiovasc Surg 1978;75:186-92.

4 Hanna ES, Ellertson DG, Jones RJ, Crew JR. Coronary artery revascularisation: re-operations performed on 124 consecutive patients. Tex Heart Inst J 1982;9: 293-7.

5 Foster ED, Fisher LD, Kaiser OC, Myers WO. Comparison of operative mortality and morbidity for initial and repeat coronary artery bypass grafting. The coronary artery surgery study (CASS) registry experience. Ann Thorac Surg 1984;38:563-70.

6 Dobell ARC, Jain AK. Catastrophic haemorrhage during redo sternotomy. Ann Thorac Surg 1984;37:273-8.

7 Cheung D, Flemma RJ, Mullen DC, Lepley D. An alternative approach to isolated circumflex coronary bypass re-operations. Ann Thorac Surg 1982;33:302-3.

8 Faro RS, Javid H, Najafi H, Serry C. Left thoracotomy for re-operation for coronary revascularisation. J Thorac Cardiovasc Surg 1982;84:453-5.

9 Ungerleider RM, Mills NL, Wechsler AS. Left thoracotomy for re-operative coronary artery bypass procedures. Ann Thorac Surg 1985;40:11-5.

10 Kolessov VI. Mammary artery-coronary artery anastomosis as method of treatment for angina pectoris. $J$ Thorac Cardiovasc Surg 1967;54:535-43.

11 Loop FD. Catastrophic haemorrhage during sternal re-entry. Ann Thorac Surg 1984;37:271-2. 